\title{
Conceptualizing School Leadership and Management From a Distributed Perspective: An Exploration of Some Study Operations and Measures
}

James P. Spillane

Kaleen Healey

Follow this and additional works at: https://repository.upenn.edu/cpre_articles

Part of the Educational Assessment, Evaluation, and Research Commons, and the Educational Leadership Commons

\section{Recommended Citation}

Spillane, James P. and Healey, Kaleen, "Conceptualizing School Leadership and Management From a Distributed Perspective: An Exploration of Some Study Operations and Measures" (2010). CPRE Journal Articles. 1.

https://repository.upenn.edu/cpre_articles/1

View on the CPRE website.

This paper is posted at ScholarlyCommons. https://repository.upenn.edu/cpre_articles/1

For more information, please contact repository@pobox.upenn.edu. 


\title{
Conceptualizing School Leadership and Management From a Distributed Perspective: An Exploration of Some Study Operations and Measures
}

\author{
Abstract \\ A distributed perspective on school leadership and management has garnered considerable attention \\ from policy makers, practitioners, and researchers in many countries over the past decade. However, we \\ should be skeptical of its appeal as a measure of worth. While optimism is high with respect to taking a \\ distributed perspective, we urge caution by arguing for more attention to research fundamentals in the \\ form of study operations and research measures before seeking causal inferences. The question is not, \\ does distributed leadership work? but rather, how are leadership and management related to school and \\ classroom conditions and school outcomes? To answer this question from a distributed perspective, we \\ need to engage study operations and measures when taking a distributed perspective in school \\ leadership and management research. This article attempts to extend that conversation.

\section{Disciplines} \\ Educational Assessment, Evaluation, and Research | Educational Leadership

\section{Comments} \\ View on the CPRE website.
}




\title{
CONCEPTUALIZING SCHOOL
}

\section{LEADERSHIP AND MANAGEMENT FROM A DISTRIBUTED PERSPECTIVE}

\author{
An Exploration of Some Study Operations and \\ Measures
}

\begin{abstract}
A B S T RA C T
A distributed perspective on school leadership and management has garnered considerable attention from policy makers, practitioners, and researchers in many countries over the past decade. However, we should be skeptical of its appeal as a measure of worth. While optimism is high with respect to taking a distributed perspective, we urge caution by arguing for more attention to research fundamentals in the form of study operations and research measures before seeking causal inferences. The question is not, does distributed leadership work? but rather, how are leadership and management related to school and classroom conditions and school outcomes? To answer this question from a distributed perspective, we need to engage study operations and measures when taking a distributed perspective in school leadership and management research. This article attempts to extend that conversation.
\end{abstract} James P. Spillane Kaleen Healey NORTHWESTERN UNIVERSITY

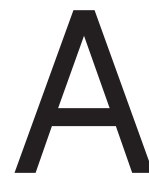

S a conceptual framework, a distributed perspective has the potential to generate new knowledge about school leadership and management (Gronn, 2000; Spillane, Halverson, \& Diamond, 2001, 2004). Scholars increasingly use a distributed perspective to frame studies of school leadership and management, with researchers from different countries often using differing conceptualizations and methodological approaches (Camburn, Rowan, \& Taylor, 2003; Harris, 2005; MacBeath, Oduro, \& Waterhouse, 2004; Spillane, Camburn, \& Pareja, 2007; Spillane, Hunt, \& Healey, 2009; Timperley, 2005). Some scholars have also taken up the challenge of examining relations between how leadership

THE ELEMENTARY SCHOOL JOURNAL VOLUME 111, NUMBER 2

(C) 2010 by The University of Chicago. All rights reserved. 0013-5984/2010/11102-0003 $\$ 10.00$ 
and management are distributed in schools and school outcomes (Heck \& Hallinger, 2009; Silins \& Mulford, 2002). Still, much of the empirical work to date has been descriptive, sometimes focused on hypothesis generation and theory development. Although often portrayed, at least implicitly, as inferior to research that seeks to test hypotheses or predict outcomes, more descriptive work is necessary to improve our understanding of how leadership is distributed in schools so that we can then explore how these arrangements influence school outcomes.

The distributed perspective's appeal to scholars suggests that it has some utility in framing and focusing research studies and some promise in extending the extant empirical knowledge base on elementary school leadership and management. However, appeal or popularity, though necessary, is insufficient. Whether a distributed perspective realizes its potential as a conceptual framework and makes a unique contribution to scholarship on leadership and management will depend on how scholars use the perspective to frame their research. At least three distinct though closely related areas of work are essential in this regard. First, while most of the writing on distributed leadership has focused on developing the theoretical or analytical frame, more work is still needed, especially work that explores different emerging conceptualizations and their implications for scholarship. The primary goal of such work should be to sharpen the analytical tools that researchers can apply in their empirical work. Loose constructs contribute to fuzzy scholarship as researchers easily talk past one another with broad constructs or ideas that denote very different concepts from one person to the next, thereby creating a false sense of consensus.

Second, the development of study operations is especially critical for translating theoretical and analytical ideas into measures for data collection and analysis, enabling the distributed framework to be used systematically in research studies. Study operation refers to the definition and specification of an aspect of a conceptual or analytical framework so that the framework can be measured based on observations in the field. The operationalization of theoretical or analytical ideas in the distributed perspective has received short shrift to date. This work will involve developing study operations and measures of different aspects of school leadership and management when viewed through a distributed lens that can be used to gather and analyze data. A key part of this work has to be a critical appraisal of what these study operations include and exclude. Such work is essential so that the field moves beyond relying chiefly on repackaging or relabeling existing measures to fit with a distributed perspective. While we can, and indeed should, salvage existing measures whenever possible in applying a distributed perspective, an exclusive focus on salvaged measures runs the risk of a distributed perspective becoming simply a new label for old and familiar constructs: It increases the likelihood that a distributed perspective simply becomes a catchall for any attempt to share or delegate leadership (Harris, 2005).

Third, most of the work to date has relied on a handful of research instruments that have dominated research on school leadership and management-especially school staff surveys, structured and semistructured interviews, and open- and closed-ended observations. Using a distributed perspective to frame research on leadership and management, however, will very likely necessitate the development of new research instruments, or at least the redesigning of instruments borrowed from other fields, so that the instruments are properly tailored for studies of elementary school leadership and management (Camburn, Spillane, \& Sebastian, 2010; Pitts \& 
Spillane, 2009; Pustejovsky, Spillane, Heaton, \& Lewis, 2009; Spillane \& Zuberi, 2009). Hence, more work on the design and validation of research instruments is important.

The ultimate quality of any effort to make causal inferences between leadership and management, framed from a distributed perspective, and key school outcomes will be largely determined by work on construct conceptualization, study operations and measures, and instrument development. Fancy statistical methods, or even random assignment, cannot compensate for loose constructs, weak study operations, and invalid and unreliable measurement. While some recent work has attended explicitly to study operations when using a distributed perspective, more work is necessary (Camburn et al., 2003; Spillane et al., 2007, 2009).

In this article, we explore some study operations and measures for school leadership and management when conceptualized from a distributed perspective. In doing so, we argue for more work that strives to theorize about key dimensions with respect to how leadership and management are distributed in schools, consider different study operations based on these conceptualizations, and entertain possible measures for them. While this work is in part technical, it is also fundamentally conceptual as such measures have to be motivated and justified using existing theoretical and empirical work. Honing in on certain core aspects of the distributed perspective, we motivate and justify specific study operations and explore measures of these operations. Using data from the 30 elementary schools in one midsized urban school district, we examine the extent to which these measures pick up on variation between schools and then critically appraise the strengths and weaknesses of our measures. Recognizing that a distributed perspective presses for attention to both the formal and informal organization, we focus this article on the formal and informal organization and relations between these two aspects.

We discuss our particular understanding of a distributed perspective before reviewing how the distributed perspective has been operationalized in some recent empirical research. We next describe the data used in the article before turning our attention to different ways of conceptualizing, operationalizing, and measuring aspects of the formal and informal organization. We entertain several study operations, motivating and justifying these operations using the theoretical and/or empirical literature. In short, we explore the different ways in which aspects of a distributed framework might be operationalized so that we can measure these dimensions. It is important to note that our work is not meant to be exhaustive as we focus on particular aspects of the framework, and the study operations that we entertain for these aspects are limited by our data. After articulating and justifying our study operations, we explore whether our measures of these operations capture variation between the 30 elementary schools in our study.

\section{Conceptual and Empirical Anchors}

\section{A Distributed Perspective}

Before proceeding, it is important to explain what we mean by taking a distributed perspective to frame research on leadership and management (Gronn, 2003; Spillane, 2006; Spillane, Diamond, \& Jita, 2003). A distributed perspective involves two 
aspects: the leader-plus aspect and the practice aspect (Spillane, 2006; Spillane \& Diamond, 2007).

The leader-plus aspect recognizes that leading and managing schools can involve multiple individuals in addition to the school principal, including others in formally designated leadership or management positions, such as assistant principals, mentor teachers, and curriculum specialists. Among other things, the available empirical work suggests that an exclusive focus on the school principal is limiting, as other formally designated leaders play critical roles in leading and managing schools (Camburn et al., 2003; Harris, 2005; Leithwood et al., 2007; MacBeath et al., 2004; Spillane \& Diamond, 2007). Furthermore, a distributed perspective allows for the possibility that individuals without any formal leadership designation can take responsibility for the work of leading and managing in schools. Contrary to some portrayals, a distributed perspective as we understand it does not assume that everyone is or ought to have a hand in leading and managing.

At one level, the leader-plus aspect is simply about identifying those individuals involved in leading and managing in the school. By moving beyond identification of individual leaders and simple aggregations, a distributed perspective also presses us to consider how these individuals, as a collective, are arranged in carrying out the work of leading and managing. Such considerations press us to examine various factors, from the division or duplication of leadership and management responsibilities to whether and how those who have a hand in leading and managing in schools complement one another.

The leadership practice aspect foregrounds the practice of leading and managing. Defining leadership and management in terms of practice allows for the possibility that people without formal leadership designations might take responsibility for that work (Heifetz, 1994). But the practice aspect presses us to move beyond individual actions. From a distributed perspective, practice is not just about the actions of individual leaders, although they are clearly relevant, but instead is fundamentally about interactions (Spillane, 2006). Actions are insufficient in the study of leadership and management practice from a distributed perspective because practice is framed as a product of the interactions among leaders, followers, and aspects of their situation. In this framing, school staff-be they the principal, curriculum specialist, or classroom teacher - can move in and out of leadership and management roles depending on the activity or situation. Of course, regardless of their activities, formally designated leaders such as the school principal always have their assigned position. Therefore, framing leadership and management from a distributed perspective foregrounds formal and informal aspects of the school organization as well as the relationship between the formal and informal aspects.

\section{Study Operations}

As one might expect given the relative novelty of efforts to flesh out a distributed perspective, applications of the perspective as a conceptual frame in empirical work are neither uniform nor monolithic. However, some common usages are emerging, which, in our view, is healthy, as this process reflects something of a dialogue among scholars. Though often not explicitly discussed, various studies have used different study operations in framing and measuring school leadership and management from a distributed perspective. To get a sense of some of the different study operations and 
measures employed by researchers using a distributed perspective, we consider three studies that relied on questionnaires and/or interviews.

Camburn et al. (2003) surveyed teachers and formally designated school leaders in 120 geographically dispersed U.S. elementary schools, most of which were involved in one of three comprehensive school reform (CSR) models. Taking a distributed perspective, Camburn et al. (2003) operationalized leadership as a set of leadership or organizational functions (Heller \& Firestone, 1995) and surveyed formally designated leaders about their responsibility for these functions. Study participants were asked about leadership functions that fell into one of three categories: instruction, building management, and boundary spanning. Camburn et al. (2003) then examined which formally designated leadership positions took responsibility for different leadership functions, showing that while some formally designated leadership positions (e.g., school principal) were generalists performing functions that cut across instruction, building management, and boundary spanning, others tended to be specialists (e.g., CSR coaches) focused on instruction. In Camburn et al.'s (2003) study, researchers asked all formally designated leaders to report on their work responsibilities.

Leithwood et al. (2007) also took a distributed perspective in a study involving 25 secondary and 140 elementary schools in a large urban/suburban school district in Ontario. Extending Peter Gronn's (2002) work on three "holistic forms" of distributed leadership, Leithwood et al. conceptualized how leadership is distributed in schools by focusing on the extent to which the performance of leadership functions is consciously aligned across different sources of leadership. Leithwood et al. (2007) proposed four study operations. First, planful alignment denotes situations in which those responsible for leadership in a school have worked out in advance who will take responsibility for particular leadership tasks and functions. Second, spontaneous alignment, similar to Gronn's "spontaneous collaboration," denotes situations in which responsibility for leadership tasks and functions is not based on planning but rather on tacit agreements that emerge from spontaneous interactions among staff. Third, spontaneous misalignment has identical origins to spontaneous alignment but results in situations in which the sources of leadership in a school are misaligned with one another in terms of the beliefs, values, and norms communicated by different sources. Fourth, anarchic misalignment refers to situations in which some of the individuals who take responsibility for leadership in a school actively reject the legitimacy of other sources of leadership for particular tasks or functions. As a result of this conflict, particular groups of school leaders can work independently of one another, actively challenging the perspectives of other leaders and competing with them for access to resources. Leithwood and colleagues theorized how these different leadership arrangements impact school outcomes. They argued, for example, that spontaneous misalignment and anarchic alignment are likely to have negative effects on organizational performance and outcomes (Leithwood et al., 2007; Leithwood, Seashore Louis, Anderson, \& Wahlstrom, 2004).

In another study using a distributed leadership framework, Heck and Hallinger (2009) focused on sources of leadership, but from the teachers' perspective. To model distributed leadership effects on student learning, they conceptualized distributed leadership as "forms of collaboration practiced by the principal, teachers, and members of the school's improvement team in leading the school's development" (Heck \& Hallinger, 2009). Heck and Hallinger (2009) developed study oper- 
ations that tap into three aspects of distributed leadership in schools and measure these operations using survey items regarding teachers' perceptions of leadership as exercised by different sources. First, Heck and Hallinger examined teachers' perceptions of collaborative decision making about educational improvement in the school (e.g., the extent to which school leadership ensures that teachers have a major role in decisions about curriculum development). Second, they considered teachers' perceptions of the extent to which school leadership emphasized school governance that empowered staff and students, as well as encouraged commitment, participation, and shared accountability for student learning. Third, they considered teachers' perceptions of the emphasis school leaders placed on participation in efforts to evaluate the school's academic development, such as the provision of regular opportunities for all the school's stakeholders to review the school's vision and purpose.

These studies, employing a distributed framework and all focusing on sources of leadership in a school, apply different study operations and measures of how leadership is distributed. While Camburn et al. (2003) focused exclusively on the formal organization, the other studies also attend to the informal sources of leadership in a school as it is perceived by staff members. Whereas Leithwood et al. (2007) focused on the degree to which leadership is preplanned and aligned among leaders, Heck and Hallinger (2009) focused on how teachers perceive the distribution of leadership functions. Comparing and contrasting these three studies, we can identify at least three dimensions on which study operations might differ when taking a distributed perspective. One dimension concerns who takes responsibility for leadership and management; that is, among which individuals or roles is responsibility for the work distributed. Study operations can focus exclusively on the formal organization or they can also include informal sources of leadership. Another dimension is the what; that is, what aspects of the work or functional responsibilities are distributed. Both Camburn et al.'s (2003) and Heck and Hallinger's (2009) study operations attend to the what aspect but conceptualize and carve up this terrain differently. A third dimension concerns how the work is distributed, such as Leithwood et al.'s (2007) attention to spontaneous versus planned distribution, or Heck and Hallinger's (2009) focus on empowerment and collaborative decision making. As the aforementioned studies illustrate, study operations may or may not attend to any one of these dimensions. Furthermore, each dimension can be operationalized in different ways, and the resulting study operations can be combined (e.g., who takes responsibility for what functions) in ways that can accentuate differences between studies. If we took the next step and focused on the measurement of study operations, we suspect that the differences among studies would increase.

Our point here is not that any of these study operations are preferable. Indeed, we could have included three different research studies with study operations that differed from those used in the three aforementioned studies. Rather, we want to underscore that the conclusions we can draw from empirical research using a distributed framework on school leadership depend on the study operations and measures used in the research.

\section{Research Methodology}

We use data from one midsized urban school district in this article in order to examine how various aspects of a distributed framework might be operationalized 
Table 1. Elementary School Descriptive Statistics for the 2004-2005

Academic Year $(n=30)$

\begin{tabular}{lrr}
\hline Variable & Mean & \multicolumn{1}{c}{$S D$} \\
\hline Number of students & 572.60 & 122.14 \\
Number of faculty members & 45.17 & 10.03 \\
Free and reduced-price lunch eligible students (\%) & 63.61 & 21.77 \\
Caucasian students (\%) & 27.77 & 24.18 \\
African American students (\%) & 64.76 & 27.97 \\
Hispanic students (\%) & 3.36 & 4.23 \\
\hline
\end{tabular}

and measured. Furthermore, we consider whether and how our measures capture variance among the schools in our study.

\section{Site and Sample}

Data for this study come from an urban, midsized $\mathrm{K}-12$ district in the southeastern United States. For this article, we analyzed data collected using two research instruments: a principal questionnaire (PQ) and a school staff questionnaire (SSQ), both of which were administered in 2005. Twenty-nine elementary school principals completed the PQ (a Web questionnaire) in the spring of 2005, with a response rate of $97 \% .^{1}$ Also in the spring of 2005, staff members at each of the district's 52 schools, including 1,210 staff members at 30 elementary schools, completed the baseline SSQ. The elementary school response rate was $89 \%$, with school-level rates ranging from $62 \%$ to $100 \%$. Not included in the SSQ sample are art, music, and computer teachers; paraprofessionals; administrative secretaries and clerks; social workers; psychologists; and food-service workers. Descriptive statistics about the elementary schools are included in Table 1. Any additional variation in the number of respondents is due to missing data.

\section{Data Analysis}

As this article is largely descriptive, the analysis primarily includes descriptive statistics and correlations. Our primary unit of analysis is the school, with most variables representing data aggregated from individual school staff members. Given that the focus of this piece is the development of study operations and measures when taking a distributed perspective, we take up the description of the measures and the analysis involved below as we describe each measure. We use three purposively selected schools from our sample-Taylor, Hancock, and Chase-to illustrate the variance between schools on key measures. We selected these three schools in order to maximize variance on the ratio of formally designated leaders to all other staff (discussed below). These three cases take us beyond central tendencies and ranges and give the reader a sense of what some of our study operations look like in the schools.

\section{Operationalizing and Measuring Leadership and Management: Formal and Informal Aspects of the School Organization}

Conceptualizing school leadership and management from a distributed perspective, we organize our account around the formal and informal aspects of school organi- 
zation. Researchers have long concluded that the informal organization is not a mirror image of the formal organization (Dalton, 1959; Downs, 1967; Homans, 1950; Meyer \& Rowan, 1977). Formally designated leaders, for example, do not always behave as their job descriptions suggest they should. This is not simply a function of intentional subversion or the shirking of formal responsibilities on the part of organizational members; the formal organization can lend legitimacy to the organization even if it does not accurately reflect what organizational members actually do (Meyer \& Rowan, 1977). Efforts to study leadership and management need to pay attention to formal and informal aspects of the school organization and relations among the two (Bidwell \& Yasumoto, 1999; McLaughlin \& Talbert, 1993). We begin by situating our work in this article within the extant theoretical and empirical literature. We then articulate our study operations and measures for the dimension and consider the evidence on the variation among schools in our study.

Our goal is to extend the conversation about developing study operations and measurement from a distributed perspective. The study operations we propose here are not intended to supplant prior study operations but rather to supplement them so as to extend the dialogue about operationalizing a distributed perspective in research. Our efforts are constrained by our current empirical work. Hence, we make no claims with respect to being exhaustive or comprehensive in our treatment.

\section{The Formal Organization}

Prior empirical work suggests that an exclusive focus on the school principal is indeed shortsighted in studying school leadership and management (Harris, 2005; Leithwood et al., 2007; MacBeath et al., 2004; Spillane \& Diamond, 2007). Previous research on schools has shown that an array of formally designated leaders have a hand in leading and managing schools, though their responsibilities differ depending on their position (Camburn et al., 2003; Heller \& Firestone, 1995; Spillane, 2006). Camburn et al.'s (2003) previously discussed study of more than 100 U.S. elementary schools found that responsibility for leadership functions was typically distributed across three to seven formally designated leadership positions per elementary school. Camburn et al. (2003) surveyed formally designated leaders in each school to examine the distribution of responsibility for leadership functions. Such positions included principals, assistant principals, program coordinators or facilitators, subject area coordinators or facilitators, mentors, master teachers, teacher consultants, and other auxiliary professional staff such as family outreach workers.

In acknowledging that an array of formally designated leaders may have a hand in the work of leading and managing, the practice aspect of a distributed perspective presses us to consider this team of leaders not only in the aggregate, but also in interaction with each other and with the rest of the organization. We consider the formally designated leadership team from three perspectives, suggesting three different study operations and specifying measures for each operation: the relative size of the team of formally designated leaders, the extent to which occupants of a particular position have a focused role, and the diversity of the leadership team. The SSQ included items about formally designated leadership positions, time use, and responsibilities. We identified these other formally designated leaders by a survey item asking whether the respondent holds a formally designated leadership position. School staff were also asked to indicate their appointment and teaching responsibil- 
Table 2. Formally Designated Leaders per School $(n=30)$

\begin{tabular}{|c|c|c|c|c|}
\hline Variable & Mean & $S D$ & Min & $\operatorname{Max}$ \\
\hline $\begin{array}{l}\text { Number of staff per school with a formally designated leadership } \\
\text { role }\end{array}$ & 12.20 & 2.98 & 5.00 & 17.00 \\
\hline Percent of staff with a formally designated leadership role & 30.15 & 6.44 & 13.51 & 41.67 \\
\hline Ratio of formally designated leaders to all other staff & .44 & .13 & .16 & .71 \\
\hline $\begin{array}{l}\text { Number of staff with a full-time formally designated leadership } \\
\text { role }\end{array}$ & 4.77 & 1.63 & 2.00 & 8.00 \\
\hline $\begin{array}{l}\text { Percent of staff with a full-time formally designated leadership } \\
\text { role }\end{array}$ & 11.68 & 3.49 & 5.41 & 18.92 \\
\hline Ratio of full-time formally designated leaders to all other staff & .13 & .05 & .06 & .23 \\
\hline $\begin{array}{l}\text { Percent of formally designated leaders that are full-time leaders } \\
\text { Full-time formally designated leaders with just one leadership }\end{array}$ & 39.82 & 13.05 & 20.00 & 80.00 \\
\hline $\begin{array}{l}\text { role } \\
\text { Numbr of roles renorted by full-time formally designated }\end{array}$ & 2.27 & 1.09 & 1.00 & 4.00 \\
\hline $\begin{array}{l}\text { Number of roles reported by full-time formally designated } \\
\text { leaders with multiple roles }\end{array}$ & 4.14 & 1.48 & 2.00 & 8.50 \\
\hline
\end{tabular}

ities, which allowed us to differentiate formally designated leaders whose primary responsibility was classroom teaching from those whose primary responsibility was leading and managing. We use the term full-time formally designated leader to refer to those formally designated leaders who were not the primary instructor for any classes during a typical school day, signaling that administration rather than teaching was their primary responsibility.

Leader to staff ratio. The sheer number of formally designated leaders in a school is likely in part a function of school size; as schools vary tremendously in terms of size, we do not simply want to know how many leaders are in a school. Hence, a more descriptive measure of the number of formal leaders in a school might be the ratio of formally designated leaders to school staff. Using a ratio instead of a net count provides more information about the prevalence of formally designated leaders relative to staff without a leadership designation. We consider a number of different measures including full-time and part-time formally designated leaders to school staff. Our rationale here is relatively simple: there is likely to be more support available to teachers when there are more formally designated leaders available to school staff.

Approximately $30 \%$ of elementary school respondents reported having a formally designated leadership role in their school. ${ }^{2}$ Table 2 shows that, including the school principal, the average school in our sample had approximately 12 formally designated leaders, though the number of formally designated leaders ranged from 5 to 17 . As discussed previously, the number of formally designated leaders is largely driven by school size (Pearson's correlation $=.641, p<.001$ ), so the ratio of formal leaders to all other staff may provide more information about the distribution of formally designated leadership positions among elementary schools.

Our analysis suggests substantial between-school variation in the number of formally designated leaders for each staff member. As displayed in Table 2, the formally designated leader to all other staff ratio ranged from 1:6.4 to 1:1.4. ${ }^{3}$ We focus on the formally designated leader to other staff ratio, rather than the leader to student ratio, because most of the work on the effects of school leadership and management on student achievement suggests an indirect relationship mediated by school and classroom conditions. This suggests substantial differences between schools in terms of the number of formally designated leaders available to offer guidance and support to 
Table 3. Case Study School Characteristics for the 2004-2005 Academic Year

\begin{tabular}{lccc}
\hline Variable & Taylor & Hancock & Chase \\
\hline Number of students & 530 & 459 & 587 \\
Number of faculty members & 39 & 38 & 53 \\
Free or reduced-price lunch eligible students (\%) & 38.1 & 69.9 & 58.9 \\
Caucasian students (\%) & 44.3 & 4.6 & 20.3 \\
African American students (\%) & 47.6 & 91.3 & 69.5 \\
Hispanic students (\%) & 1.1 & .7 & 3.1 \\
Years principal has been principal at the school & 6 & 2 & 5 \\
\hline
\end{tabular}

other school staff, who are mostly classroom teachers with no formal leadership designation. Indeed, aside from the principal, the vast majority of formally designated leaders (89\%) reported engaging in activities that support classroom instruction as part of their leadership role. These activities included practices such as modeling instructional practices, discussing student work and standardized test results, and monitoring classroom instruction. At one school, at least in theory, there was a formally designated school leader to provide support for practically every other staff member, whereas in another school each formally designated school leader had to support six other staff members. Ignoring how these formally designated leaders were assigned or their capacity to support staff, the level of support from formally designated leaders, as measured in terms of their numbers relative to other staff members, suggests tremendous variation between schools. Still, it is important to take into account that the schools with the lowest leader to staff ratios serve the most challenging student populations (e.g., Title I students), so that the low ratio of formally designated leaders to other staff may be consumed in working directly with students and addressing the extra demands placed on classroom teachers in these schools.

To illustrate these differences, consider three schools in our study. Demographic information about each school is shown in Table $3 .{ }^{4}$ Taylor Elementary School ${ }^{5}$ served 530 students in the 2004-2005 school year, roughly $38 \%$ of whom received free or reduced-price lunch. Roughly half of the students were Caucasian and half were African American, though there were a few Hispanic students. The school had 39 staff members, and the principal was in his sixth year as a principal in the district with all 6 years having been spent at Taylor. Hancock Elementary School had 459 students and 38 staff members, including the principal who was in her second year as principal at the school, though she had 10 years of experience as a principal in the district. Over $90 \%$ of the students were African American and nearly $70 \%$ of the students received free or reduced-price lunch. At Chase Elementary School, there were 587 students and 53 staff members. The principal had 16 years of experience as a principal in the district, 5 years of which occurred at Chase. Approximately $70 \%$ of the students were African American, while $20 \%$ were Caucasian, and nearly $60 \%$ of the students received free or reduced-price lunch.

There were substantial differences in the ratio of formally designated leaders to all other staff at these three schools. With a ratio of 1:1.5, Taylor School had one formally designated leader for roughly every 1.5 staff members. These formally designated leaders included the principal, an assistant principal, three reading/language arts coordinators and multiple whole school reform coaches, special program (i.e., Title I) coordinators, school improvement coordinators, mentor teachers, and teacher 
consultants. No respondents from Taylor reported being math coordinators. With a ratio of 1:2.2, Hancock School had one formally designated leader for roughly every two staff members. These formally designated leaders included the principal, three assistant principals (each of whom reported additional leadership roles), three reading/language arts coordinators, one math coordinator, and multiple whole school reform coaches, special program coordinators, school improvement coordinators, mentor teachers, and teacher consultants. With a ratio of 1:3.2, Chase School had a high formally designated leader to staff ratio with one formally designated leader for every three staff members. The 12 formally designated leaders at Chase included the principal, one assistant principal, one math coordinator, and several mentor teachers and school improvement coaches. No one who responded to the survey from Chase indicated being a reading/language arts coordinator. Looking across these three schools we see that, in theory, a formally designated leader at Chase would have twice as many staff to support compared to a formally designated leader at Taylor. We acknowledge that these comparisons are based on a number of assumptions that may not hold in practice, including the fact that other staff members are evenly distributed among formally designated leaders.

Across the 30 sample schools, we found that over half of the schools have a formally designated leader to school staff ratio between .3 and .5, that is, ranging from one formally designated leader for every two staff members to one for every three staff members. Almost one-third of the schools (nine schools) in our sample had ratios greater than .5, indicating that there was at least one formally designated leader for every two staff members.

The ratio of formally designated leaders to other staff may inflate the level of support available to staff from formally designated leaders because many of the people holding these positions in our study were also classroom teachers. Having a formally designated leadership position while also working as a classroom teacher very likely constrains the time and effort leaders devote to supporting their colleagues. Moreover, we suspect that for most of these individuals their own classroom teaching may take priority over their leadership and management responsibilities. Hence, we consider another measure: the ratio of full-time formally designated leaders to school staff. Defining full-time formally designated leaders as those who are not the primary instructor for any class during a typical day and who reported having at least one formally designated position, we found that approximately $39 \%$ of formally designated leaders are full-time leaders, indicating that $60 \%$ of formally designated leaders also had at least one classroom teaching assignment. Table 2 shows that, including the school principal, the average number of full-time formally designated leaders per school was 4.8 , with $11.7 \%$ of the professional staff having a full-time formally designated leadership position.

Looking across the 30 elementary schools, the percentage of school staff with a full-time formally designated leadership position ranged from $5 \%$ to $19 \%$. The fulltime formally designated leader to all other staff (including other formally designated leaders who are not full time) ratio then ranged from roughly 1:17.5 to 1:4.3. In other words, while one school had approximately one full-time formally designated leader for every four staff members, other schools had approximately one full-time formally designated leader for every 18 staff members, resulting in staff in one school having more than four times as much support, in terms of full-time leaders, than staff in another school. Whether or not these differences in staff assignments resulted in 
corresponding differences in terms of leadership practice, though important, is beyond the scope of this article and our data.

To illustrate these differences, consider our three case schools. With a ratio of 1:4.3, Taylor had one full-time formally designated leader for roughly every four staff members. These full-time formally designated leaders included the principal, an assistant principal, one reading/language arts coordinator and multiple whole school reform coaches, special program coordinators, school improvement coordinators, mentor teachers, and teacher consultants. With a ratio of 1:6.6, Hancock was near the middle of the distribution, with one full-time formally designated leader for roughly every seven staff members. These full-time formally designated leaders included the principal and three assistant principals, one reading/language arts coordinator, one math coordinator, one special program coordinator, and multiple whole school reform coaches, school improvement coordinators, mentor teachers, and teacher consultants. With a ratio of 1:9, Chase had a high leader to staff ratio, with one full-time formally designated leader for every nine staff members. The five full-time formally designated leaders at Chase included the principal and assistant principal, and one special program coordinator, whole school reform coach, and school improvement coordinator. There were no full-time reading/language arts or math coordinators, full-time mentor teachers, or teacher consultants at Chase. Full-time leaders at Chase had more than twice as many staff to support compared with their counterparts at Taylor. Other things being equal, staff at Chase had fewer resources in terms of full-time school leaders.

As one might expect, the full-time formally designated leader to school staff ratio provides a more realistic measure of the amount of support available to staff from the team of formally designated school leaders because it takes into account whether the formally designated leaders are chiefly responsible for leadership and management positions or a classroom teaching position. However, recognizing the formal organization as represented in formal positions is not a mirror image of the informal or lived organization, we should interpret these measures cautiously. Examining the distribution of our 30 elementary schools in terms of the ratio of full-time formally designated leader to other staff ratio, we see that the modal ratio is .09, or roughly one full-time formally designated leader for every 10 other staff members. Again, this measure varied considerably across these 30 schools.

Position focus. The ratio of formally designated leaders to school staff is one way of operationalizing leadership and management from a distributed perspective. Another dimension that merits attention concerns the extent to which those who occupy formally designated positions are focused on a single leadership position or have their time divided among multiple positions that have potentially competing responsibilities. We might label this as position focus. Another way to operationalize position focus is to consider the extent to which occupants of formally designated leadership positions report that their leadership and management responsibilities are concentrated in a particular set of functions or dispersed across multiple functions. For example, whereas the work of some formally designated leaders might be dispersed across leading and managing instruction and dealing with the external environment, others might only be focused on leading and managing instruction (Camburn et al., 2003). We describe below both formally designated leaders who have just one leadership designation and those with multiple designations.

We first consider the degree to which individual formally designated leaders in a 
school report holding a single position such as assistant principal or mentor teacher. It is possible that the more a formally designated leader's work is focused in a single position, the more likely it is that he or she will effectively and efficiently perform that position in that the single designation allows for greater focus. Furthermore, holding just one formally designated leadership position may reduce the potential for role conflict, which is heightened when an individual occupies multiple positions simultaneously. Of course, one might also argue that an individual who holds multiple formally designated leadership positions can understand the work of leading and managing school improvement from a variety of perspectives, which has potential advantages in terms of creating a more coherent improvement effort.

Of the 143 full-time formally designated leaders, ${ }^{6}$ half indicated that they were assigned to just one formally designated leadership position with the other half reporting multiple leadership positions. ${ }^{7}$ Among the full-time leaders indicating multiple positions, the mean number of formally designated leadership positions by school was 4.1. The extent to which full-time formally designated leaders held multiple leadership positions varied widely across the 30 schools. At two schools, none of the full-time formally designated leaders held multiple positions. At the same time, at 18 schools, at least half of the full-time formally designated leaders reported multiple positions. For example, at Taylor, the assistant principal also reported acting as the special program coordinator, whole school reform coach, school improvement coordinator, and teacher consultant. Occupying multiple positions, Taylor's assistant principal may be torn about which positions to give her or his primary allegiance and effort. Furthermore, to the extent that the responsibilities associated with any of these positions conflict, this assistant principal may experience role conflict. To the extent that the position of assistant principal may involve some component of evaluating teachers' classroom practice, it may conflict with the responsibilities associated with the position of teacher consultant, for which having an open and frank exchange with teachers is critical. More specifically, teachers at Taylor may be slow to seek help about instructional challenges from a teacher consultant who also evaluates them in the position of assistant principal. Similarly, each of the three assistant principals at Hancock reported at least two additional leadership positions, including reading/language arts coordinator, math coordinator, special program coordinator, whole school reform coach, school improvement coordinator, mentor teacher, and teacher consultant. At Chase, the school improvement coordinator and one of the subject area coordinators had no other formal leadership designations.

Formally designated leadership team diversity. Turning our attention to the interactions among formally designated leaders, we examine the composition of the team that does the work of leading and managing to better understand how characteristics of team members might matter to their productivity. There is considerable, if somewhat inconclusive, literature on team diversity that indicates diversity in areas such as gender, race, and experience hinders some aspects of group performance while promoting other aspects. In school leadership teams, diversity may help teams overcome coordination and motivation losses that could plague homogenous teams as they pursue school improvement efforts. A study of Chicago schools illustrates the motivation losses that can be associated with leadership-team homogeneity. In several schools in the study, a core group of senior faculty created obstacles to school reform because they had come to accept the school's dysfunctional conditions and were disinclined to make changes (Bryk, Easton, Kerbow, Rollow, \& Sebring, 1993). 
In this way, homogeneity can serve as an obstacle to progress. Diversity can enhance the performance of school leadership teams if it increases the innovation and openness to change that are necessary for school improvement (McLeod \& Lobel, 1992; Watson, Kumar, \& Michaelsen, 1993). However, diversity can also contribute to conflict and lower levels of trust among group members (Brewer, 1979; De Dreu \& Weingart, 2003; Tajfel \& Turner, 1986).

Diversity research has principally focused on relating surface-level or socialcategory differences among team members (e.g., age, gender, and tenure) to group performance (Harrison, Price, \& Bell, 1998; Pelled, 1996). Given the tendency for individuals to prefer interactions with similar others, it is not surprising that socialcategory diversity has been associated with increased conflict in groups (Jehn, 1995). Gender diversity is an especially interesting variable in educational studies, as the workforce in schools is predominantly female-unlike most organizations in traditional diversity field studies. Gender diversity has generally been associated with decreased group performance, though its effect is especially pronounced for males (Williams \& O’Reilly, 1998). While administrators are more likely than teachers to be male, there is evidence that both teachers and school leadership personnel are becoming increasingly diverse in terms of both race and gender (Loeb \& Reininger, 2004). A recent study by the RAND Corporation (RAND Education, 2004) found that women make up an increasing proportion of school administrators, and racial minorities are better represented in administrative ranks than among teachers.

Racial diversity has received less attention in organizational demography research, possibly because such little racial and ethnic diversity exists in the organizations that have been studied (Williams \& O'Reilly, 1998). Though several studies have linked racial diversity to increased creativity (McLeod \& Lobel, 1992; O’Reilly, Williams, \& Barsade, 1998; Watson et al., 1993), others have found null to negative effects on group performance (Pelled, Eisenhardt, \& Xin, 1999) and individual commitment (Tsui, Egan, \& O’Reilly, 1992). Functional background diversity, in terms of educational attainment and work experience, is believed to increase the range of information available to groups and improve their decision-making abilities (Jackson, 1992). Homogeneity in tenure is believed to promote communication and cohesion (Pfeffer, 1985), and while tenure diversity has been associated with increased conflict, its effect on performance is more complicated, albeit generally negative (Williams \& O’Reilly, 1998).

We consider the diversity of the formally designated leadership team, looking at several measures of team diversity. For categorical variables such as gender and race, the diversity index (also known as the entropy index or Shannon index) is appropriate to measure diversity within a group (Teachman, 1980). The diversity index is equal to $-\Sigma \mathrm{P}_{k} \log \mathrm{P}_{k}$ where $\mathrm{P}_{k}$ is the proportion of the group in the $k$ th category (Teachman, 1980). Higher diversity indexes reflect greater heterogeneity within the group on that attribute. Using categories and self-reported data from the SSQ and PQ, diversity indexes were computed based on the leadership teams' gender (male or female), race (Hispanic, African American, Caucasian, Asian/Pacific Islander, American Indian, biracial/multiethnic, or other), and graduate degree attainment (presence or absence).

For continuous variables, the coefficient of variation is the appropriate measure of group diversity. The coefficient of variation is calculated by dividing the standard deviation by the mean. Like the diversity index, a higher coefficient of variation 
Table 4. Formally Designated Leadership Team Diversity by

School $(n=30)$

\begin{tabular}{lcccc}
\hline Variable & Mean & SD & Min & Max \\
\hline Gender & .11 & .08 & .00 & .29 \\
Race & .36 & .11 & .09 & .58 \\
Education & .17 & .10 & .00 & .29 \\
Teaching experience & .52 & .11 & .33 & .72 \\
Experience in role at school & .68 & .22 & .27 & 1.36 \\
Experience in role in district & .64 & .16 & .41 & 1.08 \\
\hline
\end{tabular}

indicates greater heterogeneity on the team regarding that attribute. The coefficient of variation was calculated for the tenure measure and indicates variation in the number of years of teaching experience held by staff members and the principal as indicated on the SSQ or PQ, respectively.

Diversity indexes and coefficients of variation are displayed in Table 4. A Spearman rank correlation test is not significant, indicating that there is not a tendency for schools that are more diverse in one index to be more diverse in another. While it is not meaningful to compare the values of the various diversity measures with one another, looking across schools we find considerable variation with respect to the diversity of their leadership teams. Figure 1 compares the diversity of gender, race, and teaching experience for the three case schools with that of the mean of each measure across all schools. Taylor and Chase had coefficients of variation in teaching experience of .63 and .69, respectively, indicating greater diversity in terms of years of

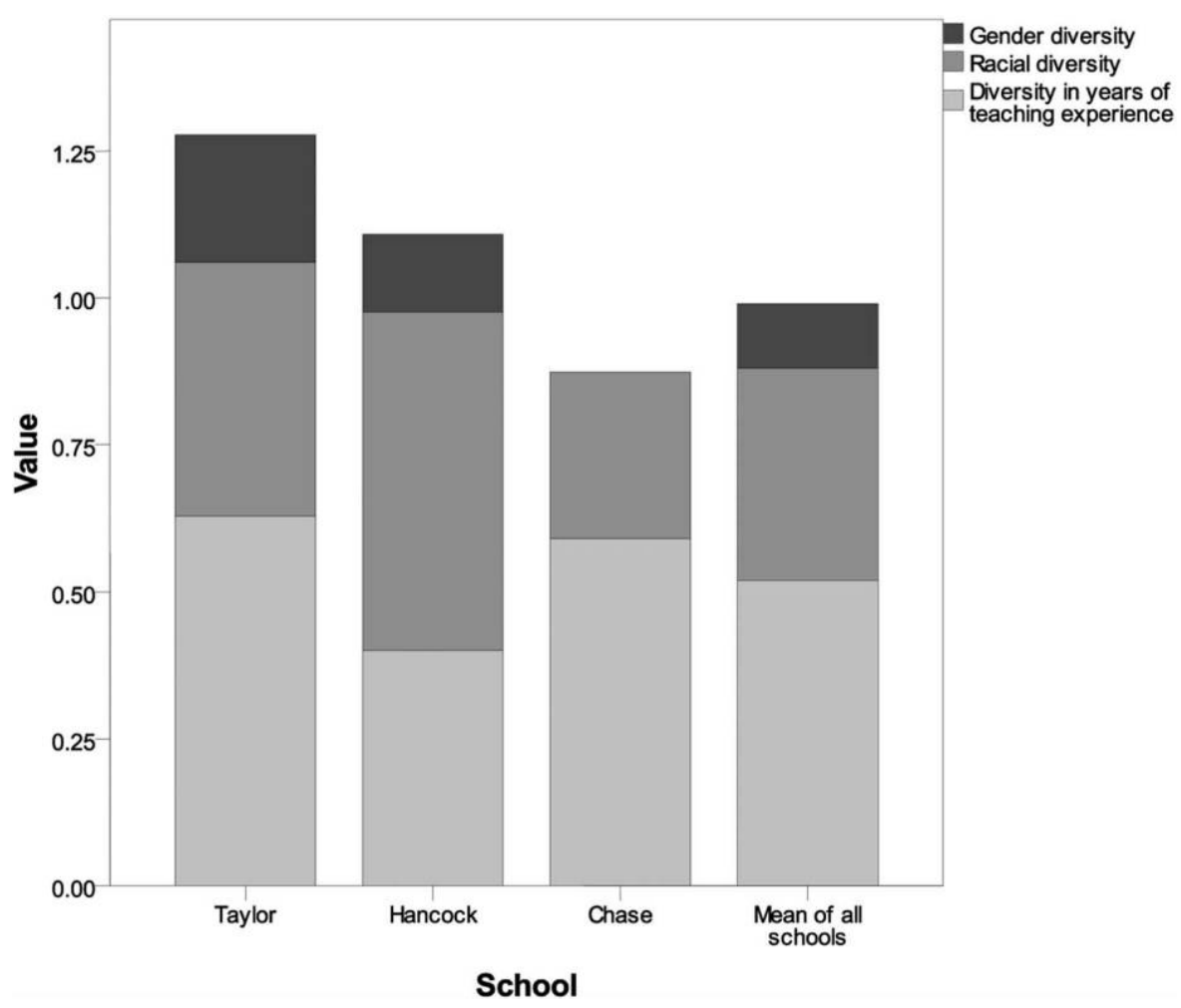

Figure 1. Diversity of formally designated leaders by school. 
teaching experience than Hancock, which had a coefficient of variation of .40. The mean coefficient of variation for teaching experience was .52 for the 30 schools in our study. To put this in more concrete terms, Taylor and Chase had formally designated leaders with between 3 and 34 years of teaching experience, with concentrations of leaders at several points in the distribution. In contrast, 8 of the 12 formally designated leaders at Hancock had 24 or more years of teaching experience.

With regard to the racial diversity measures, the leadership team at Hancock was more diverse in terms of race than Taylor or Chase's leadership teams. Hancock had a racial diversity index of .58, with three African American formal leaders, four Caucasian formal leaders, and three formal leaders who reported being multiethnic or other. This contrasts with Chase, where there was one African American formal leader and 11 Caucasian formal leaders, resulting in a racial diversity index of .28. Taylor School had a racial diversity index of .43, which included 12 formally designated leaders who were Caucasian, two who were African American, one who was Asian, and six who were multiethnic or other.

Of our three diversity indexes, there was less variation in terms of gender, though at Chase, there was no gender diversity on the formally designated leadership team as all of the leaders were women. The homogeneity of the leadership team at Chase with respect to gender is captured by a diversity index of .o, whereas the diversity indexes for gender at Taylor and Hancock were .22 and .13, respectively. Our cases and mean values, however, disguise some interesting variation between schools. For example, in eight schools, the formal leadership team was composed solely of females (as reflected in their diversity index of .o). This might be expected considering that $94 \%$ of elementary school staff in our sample were female.

Strengths and limitations. While our range of measures pick up variation across the 30 elementary schools, we also have to consider the strengths of these measures and identify limitations. As we stressed at the outset, our work is exploratory and our dataset is limited with respect to allowing us to consider the validity and reliability of our measures. Still, in this section we reflect on the strengths and limitations of our particular study operations and measures of the formal school organization.

One check on our ratios of formally designated leaders to other school staff can be determined by examining how these ratios are correlated with the school's status as a Title I school. The Title I Schoolwide Program is available to schools in which more than $40 \%$ of the students receive free or reduced-price lunch (No Child Left Behind Act of 2001, 2002), though funding is limited, so not all schools that meet the eligibility requirements receive funding. Title I schools often use the funds to hire additional staff, such as a reading specialist, to support their students' learning needs. Therefore, we would expect Title I schools to have a smaller formally designated leader to staff ratio, especially for full-time formally designated leaders. While the number of formally designated leaders, full time or otherwise, is not related to a school's Title I status, the ratio of full-time formally designated leaders is significantly lower in Title I schools (Title I schools $=.15$, non-Title I schools $=.11, p<.05$ ). On average, the Title I schools in our sample were likely to have one full-time formally designated leader for every six staff members, whereas non-Title I schools were likely to have one full-time formally designated leader for every nine staff members.

One limitation of our ratios is that we rely on survey responses to calculate all other staff rather than administrative records from the school district. Hence, our measure is potentially influenced by response rates from particular schools. While 
the overall response rate to the survey for elementary schools was $89 \%$, this ranged from a high of $98 \%$ to a low of $66 \%$ depending on the school. To check whether the response rate had influenced our ratios, we examined the correlation between the school response rate and the two ratios. We found no correlation between response rate and the ratios of formally designated leaders to all other staff and full-time formally designated leaders to all other staff. However, to avoid potentially misleading results, especially with response rates that are not as high as those obtained in the study reported here, future work might combine administrative records with survey data to calculate the formally designated school leader to staff ratios. Indeed, the leader to staff ratio could be influenced tremendously by having one formally designated school leader not respond to the survey.

We acknowledge that the ratios we describe provide a basic measure of the level of support available to school staff from formally designated school leaders. At the same time, we believe that the amount of support available to staff in terms of people and their time is important. Furthermore, combining these ratios with other measures such as the knowledge or expertise of formally designated leaders and/or the level of agreement among formally designated leaders vis-à-vis the school's instructional program can provide a more accurate assessment of the level of support from formally designated leaders.

Our indexes of diversity have at least two limitations that might be redressed in future work. Much of the work on team diversity is based on research that examines the performance of teams that work together on a project or decision-making task. Our data do not allow us to identify which of the formally designated leaders in a school actually work together in performing leadership and management tasks. In some respects, we assume a team when a team may not exist in the strict sense of that term, that is, a group of people working together on a particular task. For example, it may be that the reading/language arts coordinator, coaches, and some mentor teachers in a particular school end up working together on teacher professional development while the principal and assistant principal are not integrally involved in that work. Hence, the relevant diversity indexes might be better measured based on different subgroups of the team of formally designated leaders. Future work might ask formally designated school leaders whom they work with most in performing leadership and management tasks. Second, our measures incorporate only surface-level or social-category characteristics. In contrast, deep-level diversity reflects the differences in attitudes, beliefs, and values held by group members (Harrison et al., 1998). Over time, the effects of surface-level diversity on team outcomes weakens while the effects of deep-level diversity are strengthened, suggesting that team members who have worked together for extended periods of time may be affected more by differences in beliefs and values than by difference in race or gender (Harrison et al., 1998). Heterogeneity in values has been associated with increased task conflict, process conflict, and relationship conflict in work groups (Jehn, Northcraft, \& Neale, 1999). Diversity in perspectives about the group's goal or mission has also been shown to decrease group member satisfaction and commitment (Jehn et al., 1999) as well as organizational performance (Ostroff, 1992). With these studies in mind, future work should consider the effect of deep-level diversity among school leaders.

Another limitation of our data set with respect to exploring aspects of the formally designated leadership team in schools is that we have no direct measures of how teachers rate members of the formally designated leadership team, aside from the school principal. While some items on the SSQ ask about interactions with teacher 
leaders, it is unclear if respondents considered only teacher leaders with formally designated leadership positions. Nearly all of the other items on the SSQ that pertained to leadership and management asked about the school principal, ignoring other formally designated leaders. Considering the numbers of other formally designated leaders (both part time and full time) in the schools in the current study, future work should supplement survey questions that focus on the school principal with questions that attempt to focus, from the perspective of school staff, on the work of these other formally designated leaders. Such work would enable us to examine various issues including the extent to which other formally designated leaders can compensate for principals who are relatively weak on various measures thought critical for school improvement. Indeed, such measures would also allow us to parse out the value added by other formally designated leaders to the work of principals who score high on various measures of leadership and management.

\section{Factoring in the Informal Organization}

As noted earlier, a distributed perspective presses us to attend to both the formal and informal organization while considering the relationship between the two. An exclusive reliance on formally designated leaders and their accounts is limiting (Spillane, Camburn, Pustejovsky, Pareja, \& Lewis, 2008; Spillane et al., 2009). Studies that look beyond those individuals in formally designated leadership positions show that teachers with no formal leadership designations also perform key leadership and management functions (Heller \& Firestone, 1995; Spillane, 2006; Spillane et al., 2007; Spillane \& Diamond, 2007). Defining leadership as a set of organizational functions rather than tying leadership to a particular administrative position, Heller and Firestone (1995) found in a study of eight elementary schools that multiple individuals were taking responsibility for the work of leading and managing the schoolhouse. In other words, in order to fully understand how the work of leadership and management is arranged in schools, we have to take into account individuals who exercise leadership or management but who do not have a formally designated leadership position.

Perhaps more important than the number of individuals who perform leadership functions without a formal leadership designation, we want to know something about the relationship between formal and informal leaders in the schoolhouse and perhaps something about the composition of the formal-informal leadership team. Hence, we consider three ways to conceptualize and operationalize the relationship between the formal and informal organization. First, we examine the ratio of formal-informal leaders to school staff. Second, we consider the diversity of the formal-informal leadership team and the extent to which informal leaders may help compensate for or exacerbate the lack of diversity in the formal leadership team. Third, we consider what we term the congruence of the formal-informal organization in terms of who takes responsibility for leading and managing in the schoolhouse. We take up the operationalization and measurement of each of these perspectives separately, first justifying and motivating each before defining measures and considering what sort of variation they pick up in the schools in our study.

Leader to staff ratio reconsidered. Tapping into the informal organization and examining relations between the formal and informal is essential when taking a distributed perspective to the study of school leadership and management. Opera- 
Table 5. Informal Leaders per School $(n=30)$

\begin{tabular}{lcccr}
\hline Variable & Mean & SD & Min & Max \\
\hline Informal leaders & 3.07 & 2.90 & 0 & 14.00 \\
Percent of staff that are informal leaders & 6.87 & 5.27 & 0 & 19.72 \\
Informal math leaders & 1.77 & 1.94 & 0 & 9.00 \\
Percent of staff that are informal math leaders & 3.89 & 3.71 & 0 & 13.16 \\
Informal reading/language arts leaders & 1.97 & 1.96 & 0 & 10.00 \\
Percent of staff that are informal reading/language arts leaders & 4.35 & 3.28 & 0 & 14.08 \\
Ratio of formal and informal leaders to all other staff & .64 & .20 & .29 & 1.10 \\
\hline
\end{tabular}

tionalizations that tap into the informal organization suggest that when studying the distribution of responsibility for leadership and management, it is important to attend to school staff with no formal leadership designations. Confining our focus to leading and managing instruction in mathematics and reading/language arts - the two subjects that consume the bulk of the elementary school curriculum-we get a sense of the role of informal leaders in school leadership and management.

Two items on the 2005 SSQ ask teachers to name up to seven people in their school to whom they go for advice about their mathematics and reading/language arts instruction. For the purpose of this analysis, we consider individuals who are sought out for advice by at least three of their colleagues to be key advice givers in their school. We use the term informal leader to describe key advice givers who do not have a formally designated leadership position but do have the opportunity to exercise leadership by virtue of others seeking them out for advice. Using these criteria, we identify a total of 92 informal leaders, including 53 informal math leaders and 59 informal reading/language arts leaders out of our sample of 1,240 people (some individuals were informal leaders in both math and reading/language arts).

Table 5 shows that across the 30 schools, the mean number of informal leaders was 2.0 for reading/language arts and 1.8 for mathematics. On average, $4.4 \%$ of school staffers were identified as informal leaders in reading/language arts and 3.9\% were identified as informal leaders in mathematics. The percentage of staff identified as leaders ranged from $0 \%$ to $13 \%$ of the school staff in mathematics and from $0 \%$ to $14 \%$ in reading/language arts depending on the school. ${ }^{8}$ There was tremendous variation between schools, ranging from o to 10 informal leaders for reading/language arts and from o to 9 informal leaders for mathematics. At Taylor, for example, two informal leaders were identified, one in reading/language arts and one in math. At Hancock, we identified six informal leaders, five in math and one in reading/language arts. At Chase, three informal leaders were identified, including one each for reading/language arts and math, and one individual who was an informal leader in both reading/language arts and math.

The ratio of all leaders (both formal and informal) to all other staff also suggests tremendous variation across schools, ranging from a low of 1 to 3.5 to a high of 1 to .9. This indicates that at one school, there is one leader for roughly every 3.5 staff members, while at another school there are actually more leaders than other staff. The frequency distribution for the ratio of all leaders to other staff reveals that eight schools (including Taylor and Hancock) have ratios of at least .8o, indicating that there is nearly one leader for every other staff member.

To develop a better understanding of these ratios, especially the situations in which school leaders equal or even outnumber other staff, a closer look at the three 
Table 6. Formally Designated and Informal Leadership Team Diversity by School $(n=30)$

\begin{tabular}{lllll}
\hline Variable & Mean & SD & Min & Max \\
\hline Gender & $.06^{\star *}$ & .10 & 0 & .28 \\
Race & $.22^{\star * *}$ & .14 & 0 & .55 \\
Education & .18 & .12 & 0 & .30 \\
Teaching experience & .49 & .19 & .02 & .98 \\
Experience in role at school & $.58^{\star}$ & .25 & .08 & 1.19 \\
Experience in role in district & .63 & .19 & .17 & 1.05 \\
\hline
\end{tabular}

${ }^{*}$ Difference from formally designated leaders is significant at $p<.05$.

${ }^{* *}$ Difference from formally designated leaders is significant at $p<.01$.

${ }^{* * *}$ Difference from formally designated leaders is significant at $p<$. ool.

case schools is helpful. Furthermore, the analytical distinction between organic and mechanistic organizational arrangements may also be necessary (Rowan, 1990, 2002a, 2002b). Whereas mechanistic arrangements include centralized decision making, clearly defined positions, and hierarchical relations, organic arrangements involve staff in decision-making processes and cooperative relationships (Miller \& Rowan, 2006). While it is tempting to view schools where leaders almost equal or even outnumber other staff as more organic and less mechanistic, our case schools suggest that this may not always be the case. At Taylor the ratio of leaders to other staff was 1:1.1, but much of this was accounted for by a relatively low ratio of formally designated leaders to other staff. Indeed, only two informal leaders emerged at Taylor. At Hancock Elementary School, which was near the median in the distribution of formally designated leaders to other staff ratios, six informal leaders were identified to produce an overall leader to other staff ratio of 1:1.1. Hancock had a similar ratio of leaders to other staff as Taylor, but while Taylor's leadership was primarily composed of formally designated leaders, informal leaders made up one-third of Hancock's leadership team. Including Hancock, five schools in our sample had leadership teams for which informal leaders made up one-third or more of the team. Only three informal leaders were identified at Chase, whose formally designated leader to other staff ratio was among the highest in the sample, with a 1:2.3 ratio of leaders to all other staff.

Leadership team diversity: Compensation. It may be the case that a lack of diversity among formally designated leaders is offset by diversity among the informal leaders. However, comparing the diversity measures for formally designated leaders (see Table 4) with those for all leaders (see Table 6) reveals that including the informal leadership actually reduced the leadership team's diversity. Comparing Figures 1 and 2 illustrates that the most dramatic changes at the case study schools occurred for the gender and racial diversity measures, and, indeed, these measures are significantly lower than those that considered only the formally designated leaders. Whereas the mean gender diversity index was .11 for formally designated leaders, it was just .06 for all leaders, a difference that is significant at $p>.01$. The racial diversity index was also significantly lower; the mean for formally designated leaders was .36, and dropped to .22 when we incorporated the informal leaders.

Formal and informal congruence. Another issue concerns the alignment or match between the formal and informal organization, what we term the formalinformal organizational congruence. A distributed perspective presses us to explore 


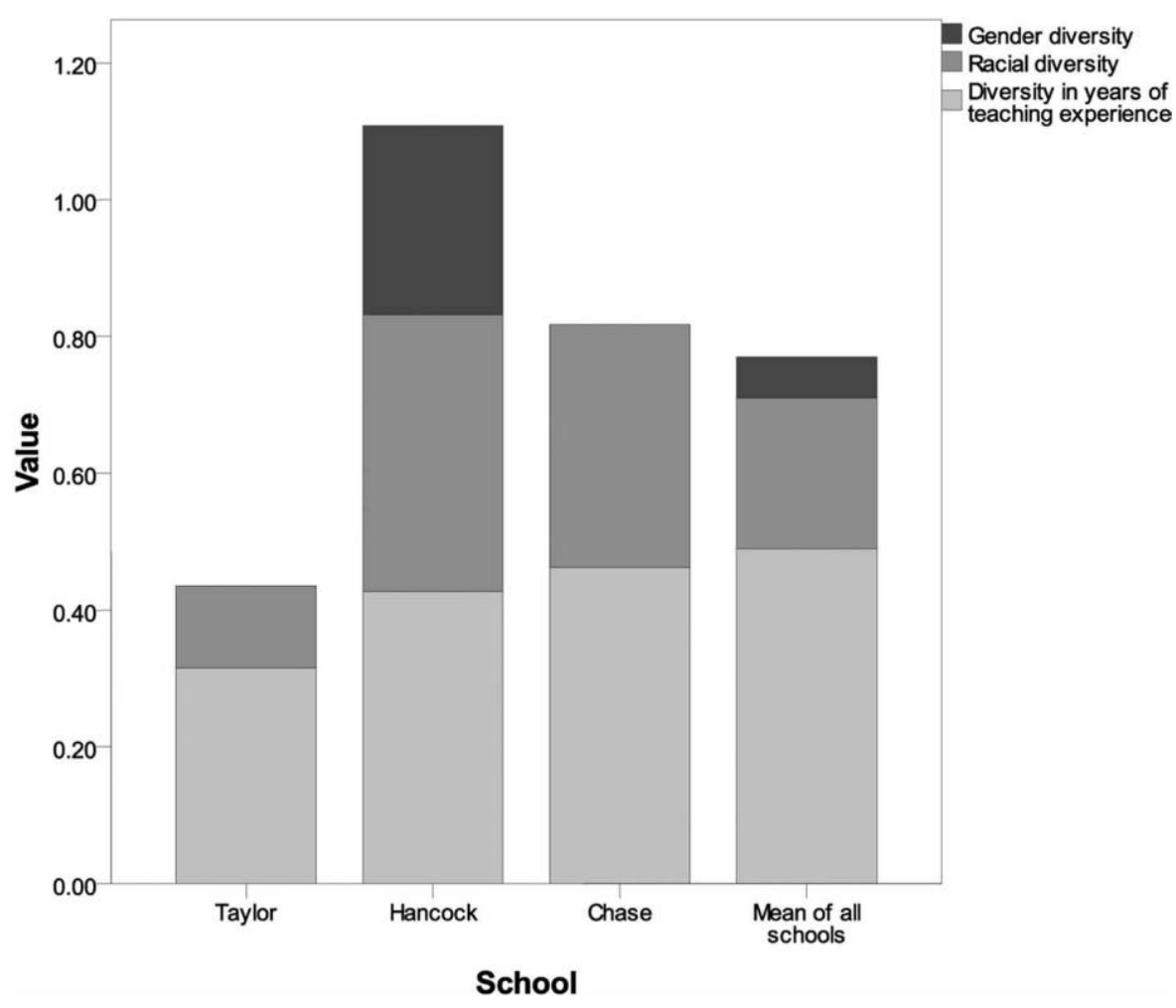

Figure 2. Diversity of all leaders (formal and informal) by school.

relations between formal and informal aspects of the organization (Spillane \& Diamond, 2007). Relations between the formal and informal can inform our understanding of school leadership and its influence on valued school conditions and outcomes. Formal and informal congruence is one attempt at capturing these relations by examining the match between formally designated leadership positions and actual advice seeking on the ground. In general, we might expect that the greater the congruence between the formal and the informal, the better for valued school conditions and outcomes, though we suspect that this relationship is neither simple nor linear. A near perfect match between the formal and informal may squelch contrary opinions and undermine the emergence of new and potentially innovative ideas from the schoolhouse floor. Furthermore, in situations where the formal leadership and management arrangements are dysfunctional, informal leaders may be key sources for change and innovation.

Overall, our analysis suggests that the formal and informal organization were not closely aligned, with many formally designated subject area leaders not figuring as prominently as one might expect in the advice networks for their school subjects. Our operationalization of informal leadership is restricted to those who are sought out for advice by three or more of their colleagues but do not hold a formally designated leadership position. To examine the extent to which the formal organization reflects the organization as lived, we must consider all individuals who are sought out for instructional advice, regardless of their leadership designation. We consider these individuals who are sought out by three or more of their colleagues to be key advice givers. Using this definition, we identified 177 individuals who are key advice givers, 
Table 7. Key Advice Givers per School $(n=30)$

\begin{tabular}{|c|c|c|c|c|}
\hline Variable & Mean & $S D$ & Min & Max \\
\hline Key advice givers & 5.90 & 3.16 & 1.00 & 17.00 \\
\hline Percent of formally designated leaders that are key advice givers & 2.83 & 1.39 & o & 5.00 \\
\hline Key math advice givers & 3.40 & 2.40 & o & 12.00 \\
\hline $\begin{array}{l}\text { Percent of formally designated leaders that are key math advice } \\
\text { givers }\end{array}$ & 1.63 & 1.10 & o & 4.00 \\
\hline Key reading/language arts advice givers & 3.77 & 2.21 & 1.00 & 11.00 \\
\hline $\begin{array}{l}\text { Percent of formally designated leaders that are key reading/ } \\
\text { language arts advice givers }\end{array}$ & 1.80 & 1.16 & o & 5.00 \\
\hline $\begin{array}{l}\text { Math advice seeking ties directed toward formally designated } \\
\text { leaders }\end{array}$ & $44 \cdot 37$ & 18.43 & 8.82 & 90.00 \\
\hline $\begin{array}{l}\text { Reading/language arts advice seeking ties directed toward } \\
\text { formally designated leaders }\end{array}$ & 46.97 & 18.93 & 3.23 & 90.32 \\
\hline
\end{tabular}

including 102 key advice givers in mathematics and 113 in reading/language arts. ${ }^{9}$ Of those individuals identified by school staff as the key advice givers in either mathematics or reading/language arts, $48 \%$ had a formally designated leadership position, whereas $52 \%$ held no such position. In other words, roughly half of the key advice givers for mathematics or reading/language arts had no formal leadership designation. For example, at Taylor, five of the seven key advice givers held a formally designated leadership position, and at Chase, three of the six key advice givers did so. In contrast, at Hancock just three of the nine identified key advice givers held a formally designated leadership position. In other words, while only a third of the key advice givers at Hancock were formally designated leaders, half of key advice givers at Chase were formally designated leaders, and nearly three-quarters of the key advice givers were formally designated leaders at Taylor. Table 7 reveals that, on average, schools had 3.8 key advice givers for reading/language arts and 3.4 for mathematics, but this ranged from zero in several schools to 12 in another school for math and from one in several schools to 11 in another school for reading/language arts. According to these study operations and measures, principals and assistant principals do not play a large role in leading mathematics and reading/language arts instruction. Only one principal emerged as a key advice giver in mathematics, with two principals emerging as key reading/language arts advice givers. Assistant principals were slightly more prominent, with eight being identified as key math advice givers and six being identified as key reading/language arts advice givers. More striking is that only $37 \%$ of the reading/language arts coordinators and $43 \%$ of the mathematics coordinators in our sample were identified by school staff as key advice givers for reading/language arts and mathematics, respectively. The proportion of reading/language arts and math coordinators who were identified as key advice givers varied by school, with anywhere from all of the reading/language arts and math coordinators also serving as key advice givers to none of them doing so.

There is considerable variation across schools in the proportion of formally designated leaders who are identified as key advice givers in either reading/language arts or math. None of the formally designated leaders were identified as key advice givers in two schools, while over $30 \%$ of the formally designated leaders were also key advice givers in seven schools. This suggests that the congruence between the formal and informal organization varies greatly by school.

We also considered a second measure of the congruence of the formal and infor- 
mal organization. Specifically, we examined what percentage of advice-seeking relations about mathematics and reading/language arts involved formally designated leaders. This analysis avoids the arbitrary nature of our cutoff point of three people seeking out an individual for advice. On average, 44\% of all mathematics adviceseeking relationships and $47 \%$ of all reading/language arts advice-seeking relationships are directed toward formally designated leaders in any position. Full-time formally designated leaders accounted for $24 \%$ of all reading/language arts ties and $14 \%$ of all math ties. School principals accounted for $2 \%$ of all reading/language arts ties and $3 \%$ of all math ties. One might expect that mathematics coordinators would play a large role in the mathematics networks, but they account for only $15 \%$ of all advice relationships. Similarly, reading/language arts coordinators account for only $17 \%$ of advice relationships in the reading/language arts networks.

Our analysis suggests considerable variation across schools, with formally designated leaders figuring much more prominently in some schools than others in the advice network as experienced by school staff. Formally designated leaders account for between $9 \%$ and $90 \%$ of mathematics advice relations and from $3 \%$ to $90 \%$ of reading/language arts advice relationships. For example, $60 \%$ of the reading/language arts advice-seeking relations were directed toward formally designated leaders at Taylor. In contrast, at Hancock, just $24 \%$ of the advice-seeking relations about reading/language arts were directed to formally designated leaders. At Taylor, then, the formal and informal organization were more closely aligned, or there was greater formal-informal congruence, at least with respect to reading/language arts instruction, compared with Hancock.

We find a positive and significant correlation between our two measures of formal-informal congruence: the proportion of formally designated leaders who are also key advice givers and the proportion of advice-seeking ties directed toward formally designated leaders. The correlation for reading/language arts is . $55(p<.01)$ and the correlation for mathematics is .50 $(p<.01)$. This suggests that while our measures are related, they are capturing different aspects of the congruence between the formal and informal organization. We also find that there is a strong correlation between the proportion of reading/language arts ties and mathematics ties directed toward formally designated leaders in a school (Pearson's correlation $=.828, p<$ .001). In other words, in schools in which formally designated leaders feature prominently in reading/language arts advice relationships, formally designated leaders also tend to feature prominently in mathematics advice relationships, and vice versa. This suggests that there may be school norms regarding appropriate sources of advice or that relations between formal and informal aspects of the organization are managed differently.

Strengths and limitations. Our measures of the informal organization and its relation to the formal organization pick up considerable variation across the 30 elementary schools in our study. While our dataset has numerous restrictions with respect to examining the goodness of our measures, we consider some issues with respect to the strengths and weaknesses of our study operations and measures below.

To begin, the ratio of key advice givers to all other staff is positively associated with deprivatized teacher practice (Pearson's correlation $=.404, p<.05$; see App. A for items). This correlation is very interesting and sensible, suggesting that the more advice available to staff, the more frequently teachers observe and provide feedback on each others' instruction. While the correlation is not large, it is significant, and we suspect that 
multiple factors, such as trust among teachers and a climate that is supportive of innovation, influence the deprivatization of teaching practice in a school.

We also find a significant relationship between the ratio of all leaders-both formal and informal - to other staff and the frequency of interactions around instruction that occur with the principal (Pearson's correlation $=.586, p<.01$; see App. A for items). This is especially interesting and suggests that principals in schools with more leaders available to each staff member engage in more frequent classroom observations. Additional measures will be required to determine if the availability of leaders frees up the principal's time for instructional observation or if the more frequent interaction with the principal drives teachers to seek out advice from their colleagues more frequently, thereby potentially creating more informal leaders.

Again, future work might improve these study operations and measures of informal leadership and management arrangements and their relations to the formal organization. To begin with, including some measures that allow for advice seeking that goes beyond mathematics and reading/language arts to teaching and learning more broadly, as well as other aspects of school life, will provide a more complete picture of the informal organization. It may be the case in some schools that informal leaders emerge in areas not directly tied to instruction, such as parent or community involvement.

With its focus on instructional advice seeking, our data also limit the extent to which we can consider formal-informal congruence, as it may be the case that the position of some formally designated leaders is not intended to provide instructional advice. For example, some formally designated leaders may provide administrative support to classroom instruction by ordering materials or scheduling professional development, but their position is not intended to serve as a source of instructional expertise. A formally designated leader who serves as a key instructional advice giver-even though that leader's position is intended to serve other functionswould actually be evidence of low formal-informal congruence, in that the organization as lived does not match the organization as designed. We also cannot speak to the motivations or school conditions that drive informal leadership. Future work should consider the extent to which informal leadership is a supplement to or a rejection of the formal organization, as well as how the formal-informal congruence relates to teacher perceptions of trust and support from their colleagues.

\section{Discussion and Conclusion}

A key challenge in using a distributed perspective to study leadership and management involves developing study operations and measures that allow the framework to be applied in research on school leadership and management. In taking a distributed perspective we have to develop study operations that allow us to describe and examine constructs in our analytical framework. Study operations are important because they influence the validity of the inferences we can make based on the data we gather and analyze. For example, our operationalization of an aspect of a distributed framework (e.g., ratio of formally designated leaders to school staff) can fail to adequately explicate that aspect, or can confound two or more aspects, and thereby pose a threat to construct validity. Further, relying on a single operationalization (i.e., mono-operational bias) or relying on a single method to gather data on a particular study operation of a construct (i.e., mono-method bias) can similarly 
threaten construct validity and call into question any inferences we can draw. We have argued in this article for attention to the development of study operations and measures when using a distributed perspective to frame investigations of school leadership and management. Such attention is critical so as to minimize threats to validity and reliability that might endanger any inferences we can make from the data. A dialogue about study operations and measures is critical if a distributed perspective is to have any chance of realizing its potential in scholarship on school leadership and management.

Taking a distributed perspective in this article, we have focused in on study operations and measures related to the formal and informal dimensions of the school organization and relations among them. In articulating these study operations we argue for more work on study operations and measurement that will lay the groundwork for future empirical work that can examine causal relations between these measures, school and classroom conditions, and school outcomes. Some scholars bemoan the weak empirical knowledge base on distributed leadership as they want solid empirical evidence with respect to whether distributed leadership works or not. We argue that they are either asking the wrong question or have oversimplified the research question. This is to be expected in the current climate as we seek causal inferences and evidence of effectiveness, forgetting that strong causal inferences depend in important part on solid study operations and reliable and valid measures of the phenomena under investigation. Randomization or sophisticated statistical techniques, though clearly crucial, do not compensate for poor study operations or invalid and unreliable measures.

As any savvy researcher understands, it is troublesome and foolhardy to design research to gauge the effectiveness of something that is weakly operationalized and poorly measured, let alone to make strong causal inferences based on the data generated from the research. The research question is not whether distributed leadership works - that is, whether it makes a difference with respect to valued school outcomes-but rather, when taking a distributed perspective, do the research questions center on how different school leadership and management arrangements or configurations relate to valued school outcomes. To investigate these research questions we have to start with serious work on study operations and measures of school leadership and management when it is conceptualized from a distributed perspective. There is no escaping this essential step. Moreover, we have to be open as scholars to engaging with our peers in the strengths and weaknesses of our study operations and measures. Maybe then and over time we can amass a body of research that will identify those dimensions of leadership and management that make a difference with respect to school outcomes.

While we have focused our article on study operations and measures, we should continue to be mindful of the challenge with respect to developing research instruments. Furthermore, not explicitly discussed in our treatment of study operations and measures is the question of whom to ask about leadership and management arrangements. Our study operations and measures focus chiefly, though not exclusively, on position and behaviors. We asked school staff if they have a formally designated leadership position, about their responsibilities, and about their advice-seeking behaviors with respect to core school subjects. A key question in all of this concerns whom and what one asks about leadership and management arrangements in schools in order to measure these arrangements. While we think behaviors are critical, we also think that tapping into norms and beliefs is equally important. Furthermore, we believe that triangulating data sources by 
asking individuals in different positions (e.g., classroom teacher, formally designated school leader) about school leadership and management is essential if we are to develop reliable and valid measures.

Future theorizing about school leadership and management from a distributed perspective would benefit greatly from careful attention to the development of study operations and measures that could inform empirical research. Indeed, it might add some discipline to the endeavor. We contend that an important step in theory building using a distributed perspective is the development of study operations grounded in empirical work, both qualitative and quantitative, in real schools. The fruits of this work will depend in large part on scholars' willingness to have a frank dialogue about one another's study operations and measures.

\section{Appendix A}

\section{Instructional Interaction Measures}

Deprivatized Practice $(\alpha=.836)$

Number of cases $=1,133$

Number of items $=4$

$(1=$ never; $2=$ a few times per year; $3=$ a few times per month; $4=1-2$ days per week; $5=$ more than 2 days per week)

This school year, how often did you observe any of the following teach?-Another classroom teacher

This school year, how often did the following observe you teach?-Another classroom teacher

This school year, how often did the following give you feedback after observing you teach?-Another classroom teacher

This school year, how often did any of the following review your students' work?Another classroom teacher

Interaction with principal around instruction $(\alpha=.720)$

Number of cases $=1,130$

Number of items $=5$

$(1=$ never; $2=$ a few times per year; $3=$ a few times per month; $4=1-2$ days per week; $5=$ more than 2 days per week)

This school year, how often did you observe any of the following teach?-The principal

This school year, how often did the following observe you teach?-The principal

This school year, how often did the following give you feedback after observing you teach?-The principal

This school year, how often did you have in depth discussions about your teaching with any of the following?-The principal

This school year, how often did any of the following review your students' work?The principal 


\section{Notes}

1. Although one principal in our sample did not respond to the questionnaire, he or she is included in the analyses involving the number of formally designated leaders in that school.

2. This includes the school principal as a formally designated leader. Approximately $28 \%$ ( 336 of 1,210 ) of respondents who were not a school principal reported holding a formally designated leadership position.

3. All other school staff includes all individuals who responded to the survey but did not indicate that they held a formally designated leadership position. Not included in the SSQ sample are art, music, and computer teachers; paraprofessionals; administrative secretaries and clerks; social workers; psychologists; and food-service workers.

4. Response rates for the sample schools were $92 \%$ for Taylor, $97 \%$ for Hancock, and $92 \%$ for Chase.

5. All school names are pseudonyms.

6. Three individuals did not respond to the item regarding the formally designated leadership positions they held.

7. Principals are assumed to have just one leadership position.

8. We need to point out two limitations with respect to operationalizing leadership using social network data. First, we define leadership for mathematics and language arts as a social influence interaction specifically related to advice and information giving. While our validity work on the instrument suggests that school staff do see advice and information giving as leadership (Pitts \& Spillane, 2009; Spillane \& Zuberi, 2009), it is not the only form, as leadership may also occur through noninteractional means such as modeling behavior or providing resources. Second, as noted earlier, the social network questions in the SSQ focused exclusively on mathematics and reading and therefore are unlikely to pick up on social influence interactions that are subjectmatter neutral or generic (e.g., classroom management, student discipline). Hence, we urge caution in interpreting these findings as they are premised on a number of assumptions.

9. Some individuals were key advice givers in both reading/language arts and math.

\section{References}

Bidwell, C. E., \& Yasumoto, J. Y. (1999). The collegial focus: Teaching fields, collegial relationships, and instructional practice in American high schools. Sociology of Education, 72(4), 234-256.

Brewer, M. B. (1979). In-group bias in the minimal intergroup situation: A cognitive-motivational analysis. Psychological Bulletin, 86(2), 307-324.

Bryk, A. S., Easton, J. Q., Kerbow, D., Rollow, S., \& Sebring, P. (1993). A view from the elementary schools: The state of reform in Chicago. Chicago: Consortium on Chicago School Research.

Camburn, E., Rowan, B., \& Taylor, J. E. (2003). Distributed leadership in schools: The case of elementary schools adopting comprehensive school reform models. Educational Evaluation and Policy Analysis, 25(4), 347-373.

Camburn, E., Spillane, J. P., \& Sebastian, J. (2010). Investigating the validity of a daily log and its utility for assessing the impact of programs on principals. Manuscript submitted for publication.

Dalton, M. (1959). Men who manage: Fusions of feeling and theory in administration. New York: Wiley.

De Dreu, C. K. W., \& Weingart, L. R. (2003). Task versus relationship conflict: A meta-analysis. Journal of Applied Psychology, 88, 741-749.

Downs, A. (1967). Inside bureaucracy. Boston: Little, Brown.

Gronn, P. (2000). Distributed properties: A new architecture for leadership. Educational Management Administration Leadership, 28(3), 317-338.

Gronn, P. (2002). Distributed leadership as a unit of analysis. Leadership Quarterly, 13(4), 423-451. Gronn, P. (2003). Leadership: Who needs it? School Leadership and Management, 23(3), 267-290.

Harris, A. (2005). Leading or misleading? Distributed leadership and school improvement. Journal of Curriculum Studies, 37(3), 255-265. 
Harrison, D. A., Price, K. H., \& Bell, M. P. (1998). Beyond relational demography: Time and the effects of surface- and deep-level diversity on work group cohesion. Academy of Management Journal, 41(1), 96-107.

Heck, R. H., \& Hallinger, P. (2009). Assessing the contribution of distributed leadership to school improvement and growth in math achievement. American Educational Research Journal, 46(3), $659-689$.

Heifetz, R. A. (1994). Leadership without easy answers. Cambridge, MA: Belknap Press of Harvard University Press.

Heller, M. F., \& Firestone, W. A. (1995). Who's in charge here? Sources of leadership for change in eight schools. Elementary School Journal, 96(1), 65-86.

Homans, G. C. (1950). The human group. New York: Harcourt.

Jackson, S. E. (1992). Team composition in organizational settings: Issues in managing an increasingly diverse workforce. In S. Wochel, W. Wood, \& J. A. Simpson (Eds.), Group process and productivity (pp. 138-173). Newbury Park, CA: Sage.

Jehn, K. A. (1995). A multimethod examination of the benefits and detriments of intragroup conflict. Administrative Science Quarterly, 40, 256-282.

Jehn, K. A., Northcraft, G. B., \& Neale, M. A. (1999). Why differences make a difference: A field study of diversity, conflict, and performance in workgroups. Administrative Science Quarterly, 44, 741-763.

Leithwood, K., Mascall, B., Strauss, T., Sacks, R., Memon, N., \& Yashkina, A. (2007). Distributing leadership to make schools smarter: Taking the ego out of the system. Leadership and Policy in Schools, 6(1), 37-67.

Leithwood, K., Seashore Louis, K., Anderson, S., \& Wahlstrom, K. (2004). How leadership influences student learning: A review of research for the Learning from Leadership Project. New York: Wallace Foundation.

Loeb, S., \& Reininger, M. (2004). Public policy and teacher labor markets: What we know and why it matters. East Lansing: Education Policy Center at Michigan State University.

MacBeath, J., Oduro, G. K. T., \& Waterhouse, J. (2004). Distributed leadership in action: A study of current practice in schools. Nottingham: National College for School Leadership.

McLaughlin, M. W., \& Talbert, J. E. (1993). Contexts that matter for teaching and learning: Strategic opportunities for meeting the nation's education goals. Stanford, CA: Center for Research on the Context of Secondary School Teaching.

McLeod, P. L., \& Lobel, S. A. (1992, August). The effects of ethnic diversity on idea generation in small groups. Paper presented at the Academy of Management Annual Meeting, Las Vegas, NV.

Meyer, J. W., \& Rowan, B. (1977). Institutionalized organizations: Formal structure as myth and ceremony. American Journal of Sociology, 83(2), 340-363.

Miller, R. J., \& Rowan, B. (2006). Effects of organic management on student achievement. American Educational Research Journal, 43(2), 219-253.

No Child Left Behind Act of 2001, 20 U.S.C. $\$ 9101$ C.F.R. (2002).

O'Reilly, C., Williams, K., \& Barsade, S. (1998). Group demography and innovation: Does diversity help? In E. A. Mannix \& M. A. Neale (Eds.), Research on managing groups and teams (Vol. 1, pp. 183-207). Greenwich, CT: JAI.

Ostroff, C. (1992). The relationship between satisfaction, attitudes, and performance: An organizational level analysis. Journal of Applied Psychology, 77 (6), 963-974.

Pelled, L. H. (1996). Demographic diversity, conflict, and work group outcomes: An intervening process theory. Organization Science, 7(6), 615-631.

Pelled, L. H., Eisenhardt, K. M., \& Xin, K. R. (1999). Exploring the black box: An analysis of work group diversity, conflict and performance. Administrative Science Quarterly, 44, 1-28.

Pfeffer, J. (1985). Organizational demography: Implications for management. California Management Review, 28(1), 67-81.

Pitts, V., \& Spillane, J. P. (2009). Using social network methods to study school leadership. International Journal of Research and Method in Education, 32(2), 185-207.

Pustejovsky, J., Spillane, J. P., Heaton, R. M., \& Lewis, W. J. (2009). Understanding teacher leadership in middle school mathematics: A collaborative research effort. Journal of Mathematics and Science: Collaborative Explorations, 11, 19-40. 
RAND Education (2004). The careers of public school administrators: Policy implications from an analysis of state-level data. Santa Monica, CA: RAND.

Rowan, B. (1990). Commitment and control: Alternative strategies for the organizational design of schools. Review of Research in Education, 16, 353-389.

Rowan, B. (2002a). Teachers' work and instructional management, Part I: Alternative views of the task of teaching. In W. K. Hoy \& C. G. Miskel (Eds.), Theory and research in educational administration (Vol. 1, pp. 129-150). Charlotte, NC: Information Age Publishing.

Rowan, B. (2002b). Teachers' work and instructional management, Part II: Does organic management promote expert teaching? In W. K. Hoy \& C. G. Miskel (Eds.), Theory and research in educational administration (Vol. 1, pp. 151-168). Charlotte, NC: Information Age Publishing.

Silins, H., \& Mulford, B. (2002). Schools as learning organisations: The case for system, teacher and student learning. Journal of Educational Administration, 4o(5), 425-446.

Spillane, J. P. (2006). Distributed leadership. San Francisco: Jossey-Bass.

Spillane, J. P., Camburn, E., Pustejovsky, J., Pareja, A. S., \& Lewis, G. (2008). Taking a distributed perspective: Epistemological and methodological tradeoffs in operationalizing the leader-plus aspect. Journal of Educational Administration, 46(2), 189-213.

Spillane, J. P., Camburn, E. M., \& Pareja, A. S. (2007). Taking a distributed perspective to the school principal's workday. Leadership and Policy in Schools, 6(1), 103-125.

Spillane, J. P., \& Diamond, J. B. (2007). Distributed leadership in practice. New York: Teachers College Press.

Spillane, J. P., Diamond, J. B., \& Jita, L. (2003). Leading instruction: The distribution of leadership for instruction. Journal of Curriculum Studies, 35(5), 533-543.

Spillane, J. P., Halverson, R., \& Diamond, J. B. (2001). Investigating school leadership practice: A distributed perspective. Educational Researcher, 30(3), 23-28.

Spillane, J. P., Halverson, R., \& Diamond, J. B. (2004). Towards a theory of leadership practice: A distributed perspective. Journal of Curriculum Studies, 36(1), 3-34.

Spillane, J. P., Hunt, B., \& Healey, K. (2009). Managing and leading elementary schools: Attending to the formal and informal organisation. International Studies in Educational Administration, $37(1), 5-28$.

Spillane, J. P., \& Zuberi, A. (2009). Designing and piloting a leadership daily practice log: Using logs to study the practice of leadership. Educational Administration Quarterly, 45(3), 375-423.

Tajfel, H., \& Turner, J. C. (1986). The social identity theory of intergroup behavior. Psychology of Intergroup Relations, 2, 7-24.

Teachman, J. D. (1980). Analysis of population diversity: Measures of qualitative variation. Sociological Methods Review, 8(3), 341-362.

Timperley, H. S. (2005). Distributed leadership: Developing theory from practice. Journal of Curriculum Studies, 37(4), 395-420.

Tsui, A. S., Egan, T. D., \& O’Reilly, C. A. (1992). Being different: Relational demography and organizational attachment. Administrative Science Quarterly, 37(4), 549-579.

Watson, W. E., Kumar, K., \& Michaelsen, L. K. (1993). Cultural diversity's impact on interaction process and performance: Comparing homogeneous and diverse task groups. Academy of Management Journal, 36(3), 590-602.

Williams, K., \& O'Reilly, C. (1998). Demography and diversity in organizations: A review of 40 years of research. Research in Organizational Behavior, 20, 77-140. 